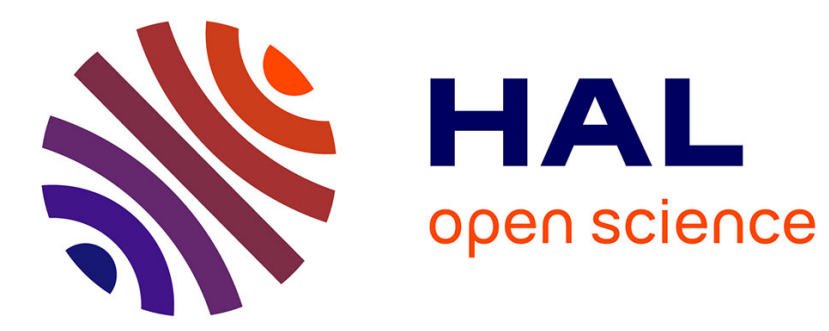

\title{
The detectable double atmospheric ducts for RFC
}

Rémi Douvenot, Vincent Fabbro, Yvonick Hurtaud

\section{To cite this version:}

Rémi Douvenot, Vincent Fabbro, Yvonick Hurtaud. The detectable double atmospheric ducts for RFC. APSURSI 2014, IEEE Antennas and Propagation Society International Symposium, Jul 2014, Memphis, United States. pp 1616-1617, 10.1109/APS.2014.6905134 . hal-01073317

\section{HAL Id: hal-01073317 https://hal-enac.archives-ouvertes.fr/hal-01073317}

Submitted on 9 Oct 2014

HAL is a multi-disciplinary open access archive for the deposit and dissemination of scientific research documents, whether they are published or not. The documents may come from teaching and research institutions in France or abroad, or from public or private research centers.
L'archive ouverte pluridisciplinaire HAL, est destinée au dépôt et à la diffusion de documents scientifiques de niveau recherche, publiés ou non, émanant des établissements d'enseignement et de recherche français ou étrangers, des laboratoires publics ou privés. 


\section{The Detectable Double Atmospheric Ducts for RFC}

\author{
Rémi Douvenot \\ TELECOM/EMA \\ ENAC, Toulouse Univ. \\ Toulouse, France, 31055 \\ Email: remi.douvenot@ recherche.enac.fr
}

\author{
Vincent Fabbro \\ DEMR Department \\ ONERA \\ Toulouse, France, 31055 \\ Email: vincent.fabbro@onera.fr
}

\author{
Yvonick Hurtaud \\ Matrise de l'Information CGN2/SDO \\ DGA \\ Bruz CEDEX, France, 35174 \\ Email: yvonick.hurtaud@intradef.gouv.fr
}

\begin{abstract}
Refractivity from clutter (RFC) systems are defined for retrieving the atmospheric ducts from the sea clutter echo of a radar in open sea or coastal environment. However, some ducts hardly have an effect on the clutter echo. Consequently, the RFC technique suffers inherent limitations and is unable to provide information about these ducts. To identify these ducts, one important parameter is the range at which a duct modifies the received power. This paper introduces the calculation of this range in the case of a double duct (evaporation and surface-based duct).
\end{abstract}

\section{INTRODUCTION}

The prediction of radar range usually assumes a standard atmosphere for the simulation. For more realistic predictions, statistical models of duct occurrence can be introduced to have statistics of the coverage depending on the day and time. More precise description can be obtained with atmospheric measurements, which is costly and difficult to deploy in operational conditions. The refractivity from clutter (RFC) technique [1] has been introduced to obtain a real-time description of the atmospheric duct. They are deduced in situ from the radar sea echos by comparisons to coverage simulations and an inversion algorithm.

In some conditions, an atmospheric duct has no effect on the clutter return, consequently it is non detectable regardless the inversion algorithm. These conditions are detailed in [2] for a trilinear surface-based duct: RFC retrievable ducts are expressed considering their descriptive parameters in relation with the maximum range of the radar. However, the presence of both an evaporation and a surface-based duct is not a rare event.

This paper introduces a means to calculate the distance at which a ray reaches the ground in the presence of a double duct. From this distance, RFC retrievable ducts can be expressed with respect to their descriptive parameters and the maximum range of the radar in the presence of double ducts following the method exposed in [2].

\section{Problem And Notations}

The double duct is described with 4 parameters that are $\delta$, the height of the evaporation duct, and $z_{\mathrm{b}}$ the height of the base of the surface-based duct, $c_{\mathrm{SBD}}$ the M-unit slope into it, and $z_{\mathrm{t}}$ its thickness, see figure 1a). This structure is supposed invariant with range. To perform analytic calculations, the evaporation duct must be linearly approximated [3]. A trilinear

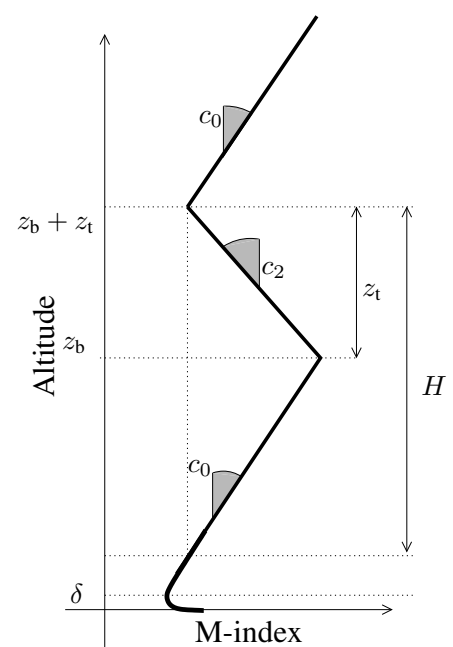

(a) Double duct

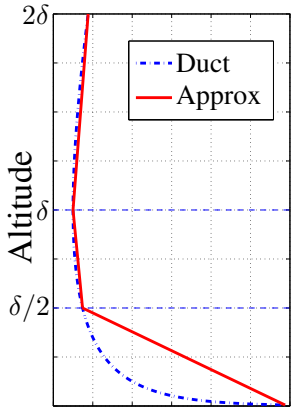

M-index tion duct

Fig. 1: A double duct and the linear approximation of the evaporation duct.

model is chosen with the interpolation points taken at $z=0$, $z=\delta / 2, z=\delta$, and $z=2 \delta$, see figure $1 \mathrm{~b}$.

The evaporation duct is supposed not strong enough to duct all the energy, and the surface-based duct strong enough to bend the energy towards the surface. In these conditions, the surface-based duct is detectable by RFC. The problem is to know, if the maximum range of the radar is fixed, what is the maximum surface-based duct height to make it detectable depending on the other parameters. This problem requires the distance at which a ray traversing the double duct reaches the sea surface. This latter calculation is detailed here.

This problem is treated analytically and compared to raytracing. The energy of the antenna is supposed confined into a cone $\left[-\theta_{6 \mathrm{~dB}} / 2, \theta_{6 \mathrm{~dB}} / 2\right]$. Then the ray corresponding to $\theta_{\mathrm{i}}=\theta_{6 \mathrm{~dB}} / 2$ is studied. If it does not reach the surface before maximum range, the duct is considered as not retrievable by an RFC system (the duct has no significant impact on the sea clutter return).

To describe a ray at one point of the trajectory, we use the altitude $z$, the distance $x$, and the angle $\theta$. Then, when $x_{z}^{\uparrow}$ expresses the distance at which the ray reaches the altitude $z$, and $\theta_{z}^{\uparrow}$ the angle to the horizontal at this very point when the ray goes upward. $x_{z}^{\downarrow}$ and $\theta_{z}^{\downarrow}$ express the same values when the 
ray goes downward.

\section{RAY TRACING}

\section{A. The Distance $x_{0}^{\downarrow}$}

The distance $x_{0}^{\downarrow}$ is the distance at which the ray reaches the ground (figure 2). It can be expressed as

$$
\begin{aligned}
x_{0}^{\downarrow} & =\left(x_{0}^{\downarrow}-x_{\delta / 2}^{\downarrow}\right)+\left(x_{\delta / 2}^{\downarrow}-x_{\delta}^{\downarrow}\right)+\left(x_{\delta}^{\downarrow}-x_{2 \delta}^{\downarrow}\right) \\
& +\left(x_{2 \delta}^{\downarrow}-x_{z_{\mathrm{b}}}^{\downarrow}\right)+\left(x_{z_{\mathrm{b}}}^{\downarrow}-x_{z_{\text {max }}}\right) \\
& +\left(x_{z_{\text {max }}}-x_{z_{\mathrm{b}}}^{\uparrow}\right)+\left(x_{z_{\mathrm{b}}}^{\uparrow}-x_{2 \delta}^{\uparrow}\right)+\left(x_{2 \delta}^{\uparrow}-x_{\delta}^{\uparrow}\right) \\
& +\left(x_{\delta}^{\uparrow}-x_{\delta / 2}^{\uparrow}\right)+x_{\delta / 2}^{\uparrow} .
\end{aligned}
$$

$x_{z_{\max }}$ is the range where the maximum altitude is reached into the surface-based duct, when the local angle $\theta=0$. Here, the antenna is supposed set at an altitude between 0 and $\delta / 2$. If the antenna is higher, the formula is adapted by removing the first terms.

The distances $x_{\delta / 2}^{\uparrow}$ and $\left(x_{\delta}^{\uparrow}-x_{\delta / 2}^{\uparrow}\right)$ are detailed below. Following [4], if the angles are low,

$$
x_{\delta / 2}^{\uparrow}=\frac{\theta_{\delta / 2}^{\uparrow}-\theta_{i}^{\uparrow}}{c_{1}},
$$

with

$$
\theta_{\delta / 2}^{\uparrow}=\sqrt{\theta_{\mathrm{i}}^{\uparrow^{2}}+2 c_{1}\left(\frac{\delta}{2}-h_{\mathrm{ant}}\right)},
$$

and

$$
c_{1}=\frac{M_{\delta / 2}-M_{0}}{\delta / 2} \text {. }
$$

Then,

$$
x_{\delta}^{\uparrow}-x_{\delta / 2}^{\uparrow}=\frac{\theta_{\delta}^{\uparrow}-\theta_{\delta / 2}^{\uparrow}}{c_{2}},
$$

with

$$
\theta_{\delta}^{\uparrow}=\sqrt{\theta_{\delta / 2}^{\uparrow}{ }^{2}+2 c_{2}\left(\frac{\delta}{2}\right)},
$$

and

$$
c_{2}=\frac{M_{\delta}-M_{\delta / 2}}{\delta / 2} .
$$

The same principle is applied along all the trajectory of the ray. Finally,

$$
\begin{aligned}
x_{0}^{\downarrow} & =\frac{\theta_{0}^{\downarrow}-\theta_{\delta / 2}^{\downarrow}}{c_{1}}+\frac{\theta_{\delta}^{\downarrow}-\theta_{\delta / 2}^{\downarrow}}{c_{2}}+\frac{\theta_{2 \delta}^{\downarrow}-\theta_{\delta}^{\downarrow}}{c_{3}} \\
& +\frac{\theta_{z_{\mathrm{b}}}^{\downarrow}-\theta_{2 \delta}^{\downarrow}}{c_{4}}+\frac{\theta_{z_{\max }}-\theta_{z_{\mathrm{b}}}^{\downarrow}}{c_{5}} \\
& +\frac{\theta_{z_{\max }}-\theta_{z_{\mathrm{b}}}^{\uparrow}}{c_{5}}+\frac{\theta_{z_{\mathrm{b}}}^{\uparrow}-\theta_{2 \delta}^{\uparrow}}{c_{4}}+\frac{\theta_{2 \delta}^{\uparrow}-\theta_{\delta}^{\uparrow}}{c_{3}} \\
& +\frac{\theta_{\delta}^{\uparrow}-\theta_{\delta / 2}^{\uparrow}}{c_{2}}+\frac{\theta_{\delta / 2}^{\uparrow}-\theta_{\mathrm{i}}^{\uparrow}}{c_{1}} .
\end{aligned}
$$

with the angles calculated following the principle of eqs. (3) and (6). Depending on the altitude of the antenna - in $[0, \delta / 2]$, $[\delta / 2, \delta],[\delta, 2 \delta]$, or above - the previous expressions must be slightly adapted.

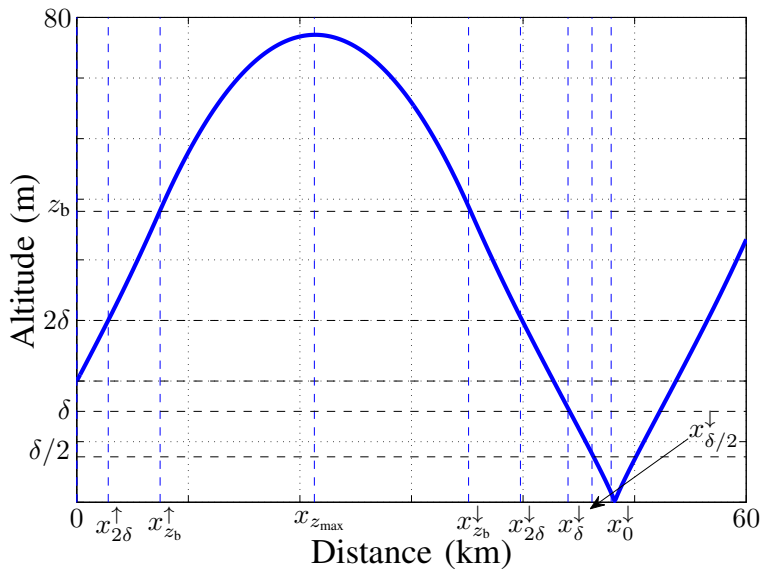

Fig. 2: Ray tracing in the presence of a double duct. The linear dotted lines indicate the analytically calculated distances.

\section{B. Simulation}

The simulation is performed in the following conditions: the antenna is set at $20 \mathrm{~m}$, with $\theta_{\mathrm{i}}=\theta_{6 \mathrm{~dB}} / 2$ is chosen equal to $3.5 \mathrm{mrad}\left(=0.2^{\circ}\right)$. The double duct verifies $\delta=15 \mathrm{~m}$ for the evaporation duct, and $z_{\mathrm{b}}=48 \mathrm{~m}, c_{2}=-0.2 \mathrm{M}$-unit. $\mathrm{m}^{-1}$, and $z_{\mathrm{t}}=50 \mathrm{~m}$ for the surface-based duct. The ray tracing with the analytically calculated distances are displayed in figure 2 .

The vertical lines in figure 2 correspond to the distances theoretically calculated. They are close to the ones obtained by ray-tracing at each step of the simulation. Then, the distance at which the ray reaches the ground can be analytically obtained with eq. (8).

\section{CONCLUSION}

A method to calculate the distance at which a ray reaches the ground in the presence of a double duct is presented and validated with an example. These formulations are useful to discriminate the ducts retrievable by an RFC system.

\section{ACKNOWLEDGMENT}

The presented work has been carried out in the framework of the French-German Technical Agreement 119 : "Modelling and measurements of sea clutter at centimetre and millimetre bands; application to atmospheric refractivity assessment" involving FHR, WTD71, DGA-MI and ONERA.

\section{REFERENCES}

[1] L. Rogers, "Likelihood estimation of tropospheric duct parameters from horizontal propagation measurements,' Radio Science, vol. 32, pp. 79-92, 1997.

[2] R. Douvenot, V. Fabbro, and K. Elis, "An introductory study for an RFC system: the detectable ducts," IEEE Transactions on Antennas and Propagation, 2014, submitted.

[3] A. Kukushkin, Radio Wave Propagation in the Marine Boundary Layer. Wiley \& Sons, 2006.

[4] L. Boithias, Propagation des Ondes Radioélectriques dans l'Environnement Terrestre. Dunod, 1983, in French. 